\title{
MISCELÁNEA
}

\section{SOBRE LA ETIMOLOGÍA DE LA VOZ BODA}

El Diccionario de la Real Academia Española hace derivar la voz boda "(del latín vota, pl. de votum 'voto', 'promesa', f. casamiento y fiesta con que se celebra" ${ }^{1}$.

Corominas, en su Diccionario crítico etimológico de la Lengua Castellana y Diccionario crítico etimológico Castellano e Hispánico, mantiene el mismo étimo y lo ilustra: "1. a doc. Alex., 1. ${ }^{\mathrm{a}}$ Crón. Gral.”, y añade: “Con la -ttodavía conservada se halla nota en el Fuero de León de 1017 (en lugar de nuptias de la otra redacción ( $R F E, \mathrm{IX}, 322$ ), uotas 'nuptias' en las Glosas de Silos, n. ${ }^{\circ}$ 248. Fuera de estas grafías latinizantes, se halla ya $b$-en los citados textos del siglo xiII ; en Neb., etc., y botum ya en inscripciones latinas (fuera de España: $C I L, V, 6.262$ ) y derivados suyos con $b$ - en glosas (CGL, V, 403.42, 349.5). Igualmente toscano boto 'exvoto', cat. (s. xIII) y port. boda 'nupcias', etc., etc. "La ac. española se encuentra ya en el latín tardío vota, en las Novelas de Justiniano y en las Decretales de Gregorio IX (Cabrera). Para cast. bodo 'voto', v. ejs. en el Glosario de Pidal al Canc. de Baena, pág. 706, etc.)." Y anota: "boda es ya corriente en las Ctgas. en el sentido moderno, y escrito siempre con $v$-: «un sartal me prestade por la mia filla trager en ssa voda», 212-26 y otros pasajes" 2 .

Nosotros, por el contrario, no creemos que la palabra boda proceda del

1 Cf. ed. 1932.

2 Cf. DCELE, Madrid, 1954, pág. 476, y DCECH, vol. I, pág. 
latín, sino que tiene su origen en la lengua árabe, como veremos después. Lo curioso del caso es que ya en el siglo xvir Sebastián de Covarrubias, en su Tesoro de la Lengua Castellana o Española, expresaba así este posible origen: "Boda y bodas. Es un término español antiguo y muy usado por lo que en latín llamamos nuptias, vel tedas, por el velo que llevava la novia ante el rostro que la cubría a modo de nube, o por las hachas que yvan con ella delante ardiendo, que antiguamente se hazían de tea, que es el coraçón del pino lleno de resina, sustenta mucho el fuego con llama. Muchos tienen por cierto que este nombre boda es arábigo, dicho cerca de los árabes buda ..." 3 . Información ésta muy importante para nuestros fines, y que el Sr. Corominas ha silenciado en el artículo correspondiente de las dos ediciones de su Diccionario, con lo que se ha vulnerado, una vez más, el carácter exhaustivo que ambas pretenden; y plenamente excusable, por otra parte, pues sus escasos conocimientos de la lengua árabe, puestos de manifiesto en muchas ocasiones, no le hubieran nunca conducido a la captura e identificación, en su terreno lingüístico, del vocablo que nos ocupa.

Sumándonos, por tanto, a esos muchos que nos cita Covarrubias que tienen por cierto que este nombre boda es arábigo, hemos consultado los grandes repertorios lexicográficos del árabe clásico, y he aquí el resultado de nuestra investigación:

Hallamos en el Sihâh, gran diccionario compuesto por el famoso gramático y lexicógrafo al-Yawhari († en 1002) *

$B u d^{c}(a)=$ 'el matrimonio', según Ibn al-Sikkit ${ }^{5}$. Se dice: Ha poseído fulano la $b u d^{c}(a)$ de fulana. Significa también la 'cohabitación'.

Donde hallamos más amplia información al respecto es en el voluminoso Lisân al-c Arab, compuesto por Ibn Manzûur (1232-1311):

$B u d^{c}(a)$, según Ibn al-Sikkit designa el 'casamiento', 'matrimonio'. También 'dote de la mujer' y 'divorcio'. Se dice "fulano ha conseguido la budc(a) de fulana cuando se ha casado con ella".

Y añade, recogiéndolo del Kitâb al-tahdî̉ del conocido filólogo al-Azharī ${ }^{B}$ :

8 Cf. ed. Martín de Riquer, Barcelona, 1943, págs. 223-224.

- Cf. Taŷ al-luga wa-Sihah al-carabiyya. Ed. Ałmad 'Abd al-Gafûr 'Attâr, El Cairo, 1956 (6 tomos), tomo III, págs. 1.176-1.178.

15 Célebre filb́logo y lexicógrafo árabe. Nació en Bagdâd hacia 802 y murió en 858. Especialista de la lexicografía y de la poesía árabe. Escribió más de 20 obras, de las que la más importante es el Kităb Islâh al-Mantiq. (Cf. EI2, tomo III, pág. 965.)

- Lexicógrafo árabe nacido en 895 y muerto en $\mathbf{9 8 0}$. Su obra principal es el diccionario titulado Kitab tahd $\imath$ b al-luga, que fue ampliamente utilizado por IBN ManzôR en su Lisân al-cArab. (Cf. $E I^{2}$, I (A-B), pág. 845.) 
La gente difiere en cuanto al sentido de $b u d^{c}(a)$, pues unos dicen que designa la 'vulva' y otros el 'coito', y también el 'contrato de matrimonio'. Se dice en un hadit : Tu $b u d^{c}(a)$ ha sido manumisa, elige, pues; es decir: tu vulva con la manumisión está libre, elige, pues, entre seguir con tu esposo o dejarlo.

\section{Al-Azharī trae este hadit referente a ${ }^{c} \bar{A}$ 'iša ${ }^{7}$ :}

Mi señor el profeta -iAlá lo bendiga y salve!- me guardó en mi casa libre de toda $b u d^{c}(a)$, es decir, de todo casamiento. Efectivamente, cuando el profeta se casó con ${ }^{c} \bar{A}$ 'iša ésta era virgen." "En la forma IV (Abdaca) significa: 'casarse con alguien'. Viene en un hadit : 'A las mujeres hay que consultarlas en lo referente a su $b_{u d c}(a)^{\prime}$.

Ha dicho Ibn al-Atîr ${ }^{8}$ :

Al-Istibdāc [Forma $\mathrm{X}$ ] es una especie de matrimonio de los tiempos preislámicos (Yāhiliyya), forma derivada de bud̆c(a) 'ayuntamiento carnal', 'cohabitación'. Consistía en que la mujer pedía ayuntarse con el hombre con el único fin de tener un hijo de él. El varón solía decir a su esclava o a su mujer : -Dirígete a fulano y pídele tener un hijo de él. Entonces la aislaba y no la tocaba para que quedase claro que su preñez era de aquel hombre. Esto se hacía únicamente por el deseo de que el hijo fuera de noble raza. Sobre esto hay un hadí que dice que ${ }^{c}$ Abd Allāh, el padre del profeta $\rightarrow$ Alá le bendiga y salve l- pasó cierto día junto a una mujer y ésta le incitó a tener un hijo de ella. Hay otro hadí de Jadîya ${ }^{\theta}$-i Alá esté satisfecho de ella!- que dice que cuando el profeta - Alá le bendiga y salve l- se casó con ella, entró a visitarle ${ }^{c}$ Amru ben Asíd y al ver al profeta le dijo: 'A esta budc(a) no hay que golpear en la nariz, que quiere decir: este es el hombre adecuado cuyo matrimonio ni se rechaza ni es indeseable'. El origen de esto está en que el macho que no es de raza cuando quiere empreñar a una camella de noble casta, le dan con un palo, $u$ otro cualquier objeto, en la nariz para que la deje y se aleje de ella ${ }^{10}$.

Traducimos, también, de $A l-Q a ̂ m u ̂ s ~ a l-M u h i ̣ t$ del gran filólogo al - Fìrūzābādī (1329-1414):

1 Hija del califa Abũ Bakr y tercera mujer y esposa preferida de Mahoma, con el que se casó en 620. Llevó, como todas las mujeres del Profeta, el título honorífico de "Madre de los Creyentes". (Cf. EI2, I (A-B), pág. 317.)

8 Célebre tradicionista, autor, entre otras obras, de un diccionario de palabras y sentidos menos corrientes hallados en las tradiciones proféticas, titulado Al-Nihaya fi garib al-hadit, y que fue incorporado al Lisan al-cArab. (Cf. EI'2, tomo III, pág. 746.)

- Primera mujer del Profeta, al que le dio cinco hijos. Como todas las mujeres del Profeta, ostentó también el título honorífico de "Madre de los Creyentes". (Cf. EI, II (E-K), pág. 911.)

10 Cf. ed. Bûlâq, El Cairo, 1890 (20 tomos), tomo IX, págs. 360-61 passimn. 
$B u d^{c}(a)$ : 'el coito', 'la vulva misma', 'dote', 'divorcio' y 'contrato de matrimonio'. Deriva del verbo badara, que significa 'rajar', 'cortar la carne', 'casarse', 'cohabitar con una mujer' ${ }^{11}$.

Por último, leemos y traducimos del gran diccionario Tây al-'Arîs, compuesto por al-Zubaydi $(\dagger 1791)$ :

$B u d c(a)$ significa: 'cortar la carne', 'rajar', y en sentido metafórico 'casarse', y en sentido figurado también 'cohabitar' ... Budc(a) significa el 'acto de cohabitar el hombre con la mujer' ... Bud c (a) indica, igualmente, 'el contrato de matrimonio ${ }^{12}$.

En los diccionarios modernos más conocidos del árabe clásico, que están basados, naturalmente, en estos más viejos y completos que antes hemos citado, la voz $b u d^{c}(a)$ aparece, en efecto, con las siguientes acepciones :

1. Dot, ce qui une femme apporte avec elle; 2 . Partie de la génération de la femme; 3 . Mariage, [nombre derivado del verbo $b a d a^{c} a$, que tiene, entre otros significados, el de] 'Couper', 'fendre', 'cohabiter avec une femme' ${ }^{13}$.

$B u d^{c}(a)$ : 'vulva', 'dote', 'matrimonio' ${ }^{14}$.

$B u d^{c}(a)$ : 'matrimonio', 'su contrato', 'vulva' '15.

$B u d^{c}(a)$ : 'parties génitales de la femme', 'hymen', 'vagin', 'vulve' || 'copulation', 'commerce charnel' ${ }^{16}$.

Naturalmente, esta palabra, con las acepciones clásicas que ya hemos visto anteriormente, fue conocida en al-Andalus, y la hallamos en un texto del siglo xv. Dice así :

Refieren los cristianos que el rey de Tudmir ${ }^{17}$ y el rey de Raiyo ${ }^{18}$, en una época muy antigua, pidieron respectivamente la mano de la hija del soberano que reinaba en Urš al-Yaman ${ }^{10}$ y el territorio vecino. La hija del rey puso, para aceptar, una condición: el que de los dos pretendientes consiguiera traer el agua desde una de las fuentes termales hasta el interior del palacio de su padre sería el más digno de su $b u d^{c}(a)$, que Lévi-Provençal, su primer

11 Cf. ed. Bûlâq, El Cairo, $1301 \mathrm{Hg}$. (4 tomos), tomo III, pág. 5 ; etiam: Tartĩb al-Qamius al-Muhït, por TÂHer AḤMad AL-ZĀWī, El Cairo, 1959 (4 tomos), tomo I, págs. 230-31.

12 Cf. ed. El Cairo, $1306 \mathrm{Hg}$. (10 tomos), tomo V, pág. 276.

18 Kazimirski, Dictionnaire Arabe-Français, t. I, s. v. bada a.

14 F. Cor rientes, Diccionario Arabe-Español, Madrid, 1977, pág. 50.

16 Cf. Al-Mucaŷam al-zvasiț. Acad. de la Lengua Árabe, El Cairo, 1973 (2 vols.), tomo I, sub voc. budc.

16 Cf. Blachère-Chouemi-Denizeau, Dictionnaire arabo-français-anglais, tomo I, págs. 661-662.

17 Sobre este nombre árabe de la provincia de Murcia, cf. $E I^{2}$, IV.

18 Nombre que los musulmanes de España dieron a la región de la que Málaga era cabeza de distrito. (Cf. Levi-Provençal, La Péninsule Ibérique au Moyen-Age, pág. 47.)

10 Sobre el nombre de este distrito, cf. Lévi-Provençal, ob. cit., pág. 47 (nota 3). 
traductor, trasladó, con cierto eufemismo, por "serait le plus digne de partager sa couche" 20 .

El término $b u d^{c}(a)$ aquí empleado lo podemos traducir con cualquiera de las diversas acepciones antes señaladas.

Por otra parte, y moviéndonos siempre en el mismo contexto semántico, he estimado interesante y oportuno señalar el sentido del verbo bad $a^{c} a=$ 'cortar', 'romper', 'rajar', de donde deriva $b u d^{c}(a)$, porque creo firmemente que está en estrecha relación semántica con el español casamiento, del que sería un calco, en el sentido latino de cassere, francés cassement, acción de casser, conservado en el francés popular "en parlant d'une jeune fille, perdre sa virginité" ${ }^{21}$, y, en modo alguno, relacionarlo con casa y menos considerarlo como un calco del árabe banâ biha, porque banâ biha significa 'consumar el matrimonio', y no "se casó (con ella) propiamente construyó (una casa) muy comprensible dentro del simbolismo oriental", como tan absurdamente pretende Corominas ${ }^{22}$. Creo que dicha expresión habría que relacionarla, en todo caso, con la idea de "tener hijos". No hay que olvidar que de esta raíz procede $i b n$ y bint, con sus correspondientes plurales, y que en su forma V (tabannâ) significa 'prohijar'.

Creemos haber exhaustivamente probado que el vocablo boda viene del árabe $b u d^{c}(a)$, como ya apuntó Covarrubias. Desde el punto de vista semántico, ha quedado ampliamente ilustrado, y desde el fonético, su paso al español no presenta el más mínimo problema: El cambio de /u/ a /o/ se justifica por hallarse en contacto con velar ${ }^{23}$. El / d/ en el interior de los arabismos en que figura este fonema se reproduce en español por $/ \mathrm{d} / . \mathrm{Ej}$., almadraba, redoma, etc., etc.; en topónimos Almadech, Almadich (prov. de Alicante), etc., etc. ${ }^{24}$, mientras que $/ c /$ final, en los arabismos donde tal fonema se halla, "desarrolla generalmente un sonido final (vocal de apoyo) cuyo timbre se aproxima al de una -a- palatal, acompañada de las vibraciones laríngeas que corresponden al $/ c /$ en la pronunciación árabe normal" ${ }^{25}$, vocal de apoyo o relajada que nosotros hemos mantenido, entre paréntesis, todas las veces que a lo largo de nuestro trabajo hemos transcrito esta palabra árabe.

20 Cf. "La péninsule Ibérique au Moyen-Age", d'aprés le "Kitâb ar-Rawud al-Mictâr fi jabar al-Aqtâr', d'Ibn 'Abd al-Muncim al-Himyarî, par LEvI-ProvençAL, Leiden, 1938, págs. 49-50 de la traducción.

21 Cf. Larousse du XXe siecle, París, 1924, pág. 33.

22 Cf. Corominas, ob. cit., tomo I, pág. 715.

28 Cf. Corriente, F., A Grammatical Sketch of the Spanish Arabic Dialect Bundle, Madrid, 1977, pág. 28.

24 Cf. Steiger, A., Contribución a la fonética del hispano-árabe ..., Madrid, 1932, págs. 163-164.

20 Cf. Steiger, A., ob. cit., pág. 289. 
Así pues, y poniendo un poco de orden en el amasijo que nos presenta Corominas, tendremos que boda, como tal arabismo, se encuentra ya documentado, con esta grafía, en cat. (s. XIII) y port. boda 'nuptias'; y corriente en las Ctgas., en el sentido moderno, formas estas últimas que Corominas, erróneamente, relaciona con el latín vota pl. de votum, como vimos al principio.

JosE VÁzQuez RuIz. 